\title{
Global prevalence of Helicobacter pylori and its effect on human health
}

\author{
Mah Noor Hassan ${ }^{1}$, Amina Arif ${ }^{1 *}$, Muhammad Saqib Shahzad ${ }^{2}$, \\ Moazzma Ibrahim ${ }^{1}$, Harris Abdul Rahman ${ }^{1}$, Muhammad Aqil Razaq ${ }^{3}$ \\ and Rafique Ahmed ${ }^{3}$
}

1. Faculty of Life Sciences, University of the Central Punjab, Lahore-Pakistan

2. Govt Model College for boys, Model town Lahore-Pakistan

3. Govt Kot Khawaja Saeed Teaching Hospital, Lahore-Pakistan

*Corresponding author's email: draminaarif@gmail.com

Citation

Mah Noor Hassan, Amina Arif, Muhammad Saqib Shahzad, Moazzma Ibrahim, Harris Abdul Rahman, Muhammad Aqil Razaq and Rafique Ahmed. Global prevalence of Helicobacter pylori and its effect on human health. Pure and Applied Biology. Vol. 9, Issue 1, pp936-948. http://dx.doi.org/10.19045/bspab.2020.90098

\begin{tabular}{llll}
\hline Received: 09/07/2019 & Revised: 19/11/2019 & Accepted: 13/12/2019 & Online First: 06/01/2020
\end{tabular}

\section{Abstract}

Helicobacter pylori infection is non-hereditary disease caused by a bacteria $H$. pylori that possess gramnegative helical morphology. H. pylori infection can cause variety of gastrointestinal problems, including stomach ulcers, inflammation in stomach linings and cancer. The $H$. pylori bacterium has infected approximately $50 \%$ of the total populations. The frequency of $H$. pylori infection varies among countries, underdeveloped countries have high ratio of cases of $H$. pylori whereas its ratio is low in developed countries. Around $70 \%$ children of underdeveloped countries may be affected by $H$. pylori infection. Noncardia gastric patient have a high chances to be infected by $H$. pylori however, the risk of gastric cardia cancer is relatively low in the H. pylori infection. Patients with weak metabolic control and poor glycemic condition especially diabetes type 2 patients are more susceptible to $H$. pylori disease. The Gastroesophageal reflux syndrome and $H$. pylori infection share an inverse relationship particularly those with CagA-positive strains, are less likely to have risk of Gastroesophageal Reflux Disease (GERD). The association of Non-alcoholic fatty liver disease (NAFLD) with H. pylori infection reveals that Cytotoxicassociated gene A (cagA) negative strain is the leading cause of $H$. pylori infection in NAFLD. Diagnosis of $H$. pylori can be performed by upper endoscopy or EGD, Breath test and stool culture. Treating H. pylori medicine with natural ingredient such as probiotic, green tea, honey and olive oil can improve the efficiency of antibacterial drug. This review demonstrates that patients of non-cardia gastritis, diabetes type 2 and NAFLD are more prone to be infected by $H$. pylori disease the ratio of $H$. pylori infection in humans can be reduced by improving domestic hygienic and sanitary infrastructure.

Keywords: Breath test; Cancer of stomach; Diabetes type 2; Endoscopy; Gastroesophageal reflux disease; Gastric cardia cancer; Helicobacter pylori; Non-cardia gastric cancer; Stomach ulcers; Stool culture

\section{Introduction}

Good nutrition is an essential for leading a healthy lifestyle. Factors for staying healthy include the healthy genetics, diet, exercise, environment, relationships and education. All these factors upgrade an individual's life style [1]. Extensive researches demonstrate that there is a link between microorganisms and their impact on human health. Most of the microorganisms are not harmful as there are trillions of microorganisms living in and on human body but some dangerous microorganisms harm human body as well as the food we eat [2]. 
Previously, Helicobacter pylori was recognized as Campylobacter pylori, $H$. pylori possess gram-negative helical morphology and is present in human stomach which induces chronic gastritis with long lasting stomach inflammation. The $\mathrm{H}$. pylori is a microaerophilic, belongs to genus Helicobacter and the genus contains about 35 species. The family of $H$. pylori is Helicobacteracea and its Phylum is Proteobacteria [3, 4].

H. pylori bacterium can be passed from one person to another simply by saliva, fecal material, vomiting and by contaminated food and water. The health problems which are related to a $H$. pylori disease includes (1) the ulcer caused by bacterium that impairs the stomach linings and form an open sore (ulcer). Many researches proof that $10 \%$ of total patients of $H$. pylori have ulcer. (2)Inflammation in stomach linings. (3) Cancer of stomach. Once H. pylori enters to stomach the acute symptoms such as nausea, bloating, burning pain in abdomen and loss of appetite are started but these symptoms become chronic infection if the bacteria succeed to survive [5].

H. pylori bacterium has infected approximately 50 percent of the total population. The occurrence of $H$. pylori transmission varies from age, race, ethnicity and geographic area. The rate of transmission of $H$. pylori in developing countries is comparatively high [6]. Moreover, the frequency of $H$. pylori diseases is reducing over the last decade in many countries but still its intensity is high in some under developed countries [7]. The decline of $H$. pylori is due to changes in the epidemiology of the bacterium which further cause changes in the epidemiology of peptic ulcer, gastroesophageal reflux disease and gastric cancer [8].

H. pylori infection is not a hereditary disease. Firstly, the bacterium enters to the stomach and after a while it starts damaging the protected lines of stomach and small intestine. Around $70 \%$ children of under developed countries may be affected by $H$. pylori infection. The cause of infection in children is contact with bacteria. A child may contact with the bacteria by not eating cleaned and properly cooked food, by drinks water which was contaminated with infected bacteria and by not washing hands properly after going to bathroom. H. pylori infection in children can be diagnosed through Stool culture (small stool is collected as a sample), Breath test (presences of carbon in child's breath) and by upper endoscopy or EGD (test check to the esophagus, stomach and intestine) [9].

Urease enzyme is secreted by $H$. pylori which helps the H. pylori to survive in the harsh acidic nature of stomach. The urease converts itself into urea $\left(\mathrm{NH}_{2} \mathrm{CONH}_{2}\right)$ and then to ammonia $\left(\mathrm{NH}_{3}\right)$. The role of ammonia is to neutralize and help the $H$. pylori to survive in high $\mathrm{pH}$ of stomach [10]. Moreover the $H$. pylori has developed a way of meddling with some immune response that makes them ineffectual in eradicating them $[10,11]$. The stomach cancer or gastric cancer which are caused by $\mathrm{H}$. pylori has two main types first one is the gastric cardia that affects the top most inch of stomach and then causes cancer over there while non-cardia gastric causes cancer of all other sides of stomach.

Gastric cancer has killed around 738,000 people year around a year and has become the second most fatal cancer of the world [10]. It is a common type of cancer in South America and Asia rather than the western countries and US. A number of studies have revealed that the ratio of non-gastric cardia cancer is decreasing but the ratio of gastric cardia cancer has risen $[10,12]$. People infected by $H$. pylori become more susceptible to develop non-cardia gastric cancer whereas gastric cardia cancer risk factor is low [12]. Certain stains of $H$. pylori carry a needle-like attachment called CagA (cytotoxic- 
associated gene A). After attaching with the stomach lining it alters the stomach cell structure and form a long term attachment with stomach and causes chronic inflammation [12]. Nevertheless, not all strains of $H$. pylori bacterium possess CagA gene those bacterium which have such gene are identified as CagA-positive $H$. pylori [13].

H. pylori disease and Diabetes mellitus are the two independent diseases. It was discovered that the metabolic control and poor glycemic condition increases the risk rate in a person to have of $H$. pylori infection [14]. Gastrointestinal diseases is the most common problem which a diabetic patient mostly complained that is occurred due to the existence of $H$. pylori bacterium. The diabetes type 2 patients are more prone to $H$. pylori infection $[15,16]$.

Gastroesophageal reflux disease causes heartburn, burning of esophagus and tissue damage. There is an inverse relationship between gastroesophageal reflux and $H$. pylori transmission. Many studies suggested that $H$. pylori may shield against the developing of GERD or it may reduce it [17, 18]. Conversely, few studies also suggest that it may worse the GERD. The rate of $H$. pylori infection is lower in developed nations such as Australia, North America and Western Europe whereas GERD ratio is higher over there $[18,19,20]$. In contrast, the frequency of $H$. pylori diseases is high in developing countries such as Europe, Africa, India, China and South America while GERD frequency is lower in them [21, 22, 23, 24]. Non-alcoholic fatty liver disease (NAFLD) is basically a sort of liver injury induced by insulin resistance (IR), metabolic stress and genetic susceptibility. Infection caused by $H$. pylori bacterium is not only linked with gastrointestinal diseases such as biliary or liver, cardiovascular diseases but also with the upper gastrointestinal tract disease. The link between NAFLD and $H$. pylori infection is controversial but recent study suggested that there is an association between NAFLD and the $H$. pylori cagA-negative strain. The risk factor of cagA-negative strains is high in NAFLAD as we compare it with cag-A positive strain $[25,26,27]$.

Doctors usually recommend a combination of an acid-reducing medication and two antibiotics for treating $H$. pylori infection and this mixture is known as the triple therapy. Treatment of $H$. pylori infection takes about 10 days to 2 weeks. The reason for using two antibiotics instead of just one because it reduces the risk of antibiotic resistance in patient. Some antibiotics like Tetracycline, Clarithromycin, Amoxicillin and Metronidazole are used in the treatment of $H$. pylori. Acid-reducing drugs help to heal the stomach lining. To heal stomach, acidreducing drugs like Proton pump inhibitors; pantoprazole and omeprazole are used. Furthermore histamine blockers; ranitidine ( Zantac) and cimetidine (Tagamet) that inhibits acid-triggering histamine, another acid-reducing medicine, bismuth subsalicylate (Pepto-Bismol) that protects and coats the stomach lining of patient.

There are some natural treatments that increase the efficiency of conventional drugs, they are used in $H$. pylori treatment. Probiotic are the good bacteria that help in digestion, taking probiotics before or after standard $H$. pylori medicine may enhance their working rates. Drinking green tea and using honey, olive oil, broccoli and licorice root in diet have some antibacterial properties when taken against the $H$. pylori disease [28].

The rate of $H$. pylori attack can be decreased by improving household hygienic and sanitary infrastructure. There are several important steps for decreasing the prevalence of $H$. pylori infection i.e. washing hands thoroughly, eating food that is clean and properly cooked, by drinking clean water, by quitting smoking and reducing alcohol intake [29]. 


\section{Classification of $\boldsymbol{H}$. pylori}

Helicobacter pylori possess gram-negative helical morphology as shown in figure 1 and the bacterium which is about $0-5$ micrometer in the diameter and 3 micrometers long. $H$. pylori has micro aerophilic characteristic means it require oxygen for fermentation and respiration [30]. The bacterium have 5-7 flagella [31] and also contains hydrogenase enzyme that accelerates oxidation of hydrogen and let bacterium to use hydrogen in place of an energy source for their growth. Molecular structure of $H$. pylori has urease enzyme which helps it to penetrate into the mucosa of stomach. Moreover, it secretes the urease enzyme which exchanges urea into bicarbonate $\left[\mathrm{HCO}_{3}\right]$ and ammonia $\left[\mathrm{NH}_{4}\right]$. Acidic environment of stomach kills the bacteria so its neutralization is important, after the discharge of ammonia, the ammonia plays its role by neutralizing the acidic environment of stomach. Some other products of $H$. pylori, include protease, mucinase and phospholipases degrade gastric mucus. The lipopolysaccharide of bacterium when released in the circulation, has a powerful endotoxin activity which causes acute inflammation [30].

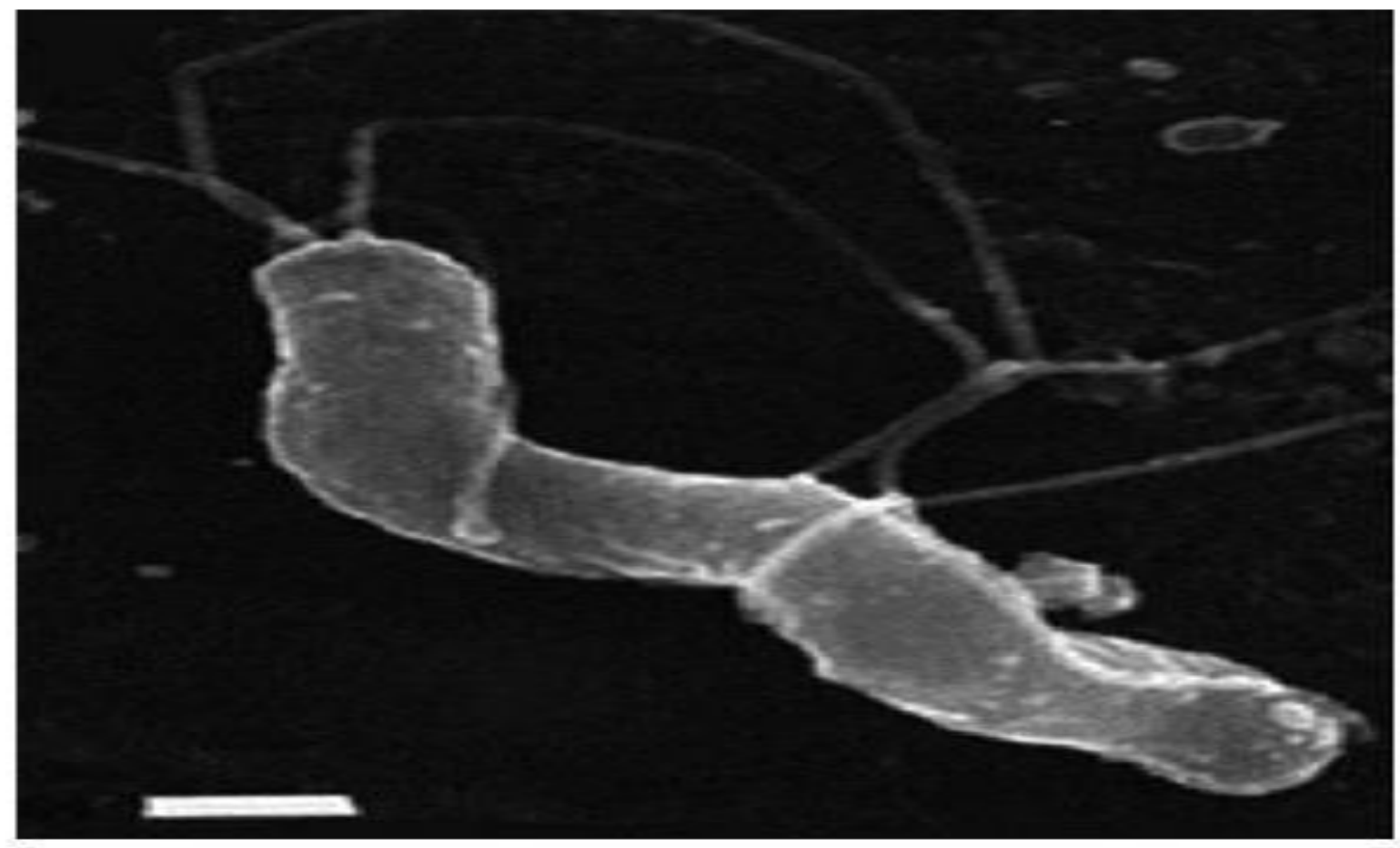

Figure 1. Morphology of helicobacter: Spiral shaped $H$. pylori with five to seven wrapped polar flagella [32]

\section{Complications and symptoms of $\boldsymbol{H}$. pylori} H. pylori is a clever microorganism that has unbelievable adaptive advantages which enable it for surviving in the acidic nature of stomach. The symptoms of $H$. pylori in an infected person are shown in (Figure 2).

\section{Ulcer}

H. pylori can cause chronic inflammation which is due to the damaging of lining of stomach and small intestine. It is an estimate that approximately $10 \%$ of $\mathrm{H}$. pylori patients have chances to develop stomach ulcer. 


\section{Inflammation in the stomach lining}

H. pylori infection causes gastritis by interfering with stomach which further cause chronic stomach pain.

\section{Stomach cancer}

In some cases, stomach cancer can be resultant from $H$. pylori infection, which is the last stage of the $H$. pylori infection [28].

\section{$H$. pylori Infection Symptoms:}

The $H$. pylori transmission becomes chronic leading to ulcer, symptoms of it includes, abdominal pain, especially in empty stomach. There are numeral other symptoms which are associated with $H$. pylori infection, they are gnawing pain, lack of appetite, excessive burring, bloating, heartburn, nausea and fever [28].

\section{Prevalence of $\boldsymbol{H}$. pylori infection}

The existences of $H$. pylori infection globally is overall high in developing countries and the infection occurs more in young age. The rate is 0.5 percent in developed countries and 3-10 percent each year in underdeveloped countries. Worldwide, one billion people are predicted to be sick with $H$. pylori. Global prevalence frequency is shown in figures 3 and $4[6]$.

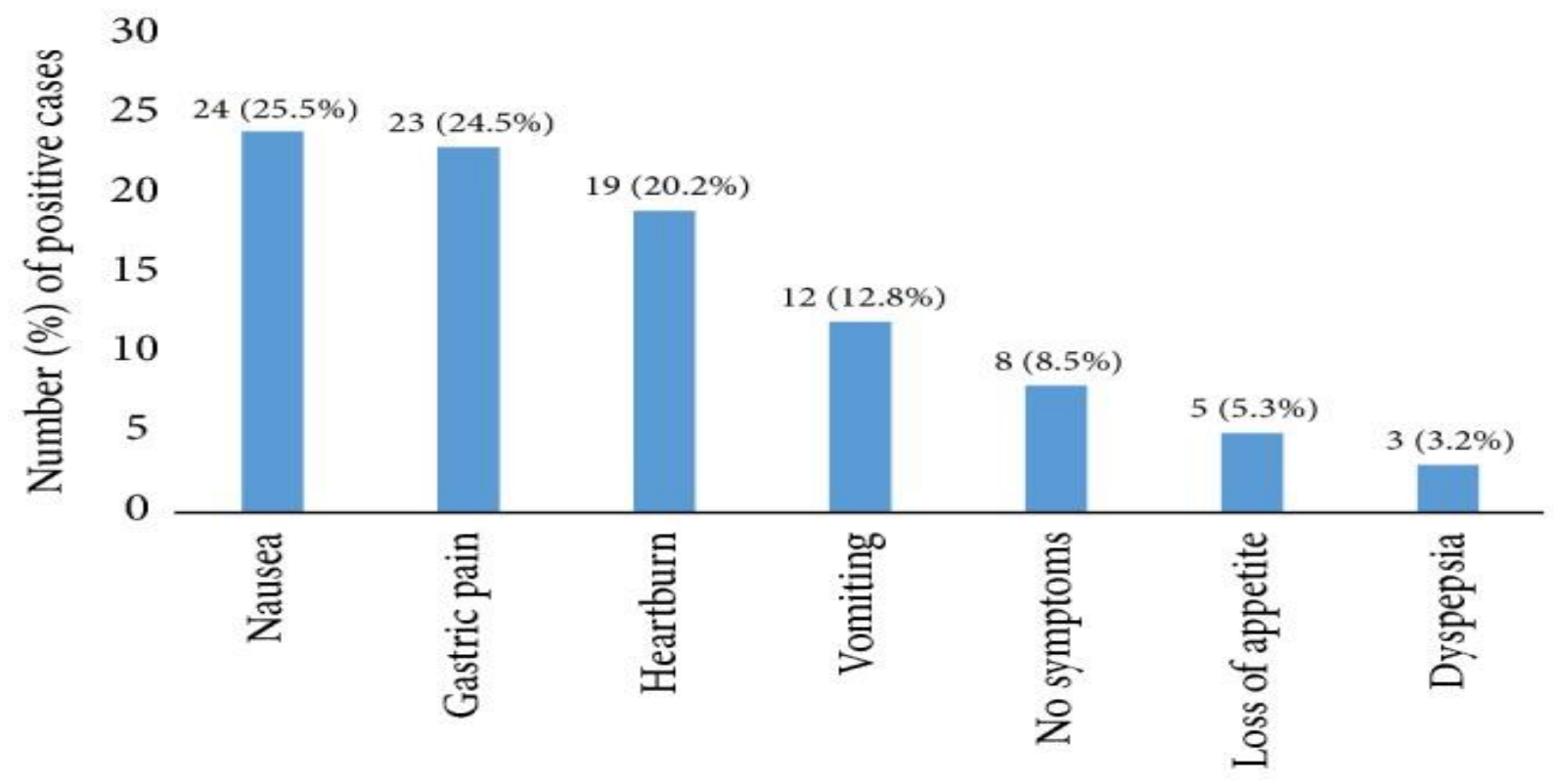

Signs and symptoms

Figure 2. The symptoms of $\boldsymbol{H}$. pylori in an infected person. Out of $25 \%$ cases of $\mathrm{H}$. pylori, $24 \%$ were infected with nausea, $23 \%$ were infected with gastric pain, $19 \%$ suffered from heartburn, $12 \%$ suffered from vomiting, $8 \%$ with no symptoms, $5 \%$ with loss of appetite and 3\% had dyspepsia [33] 


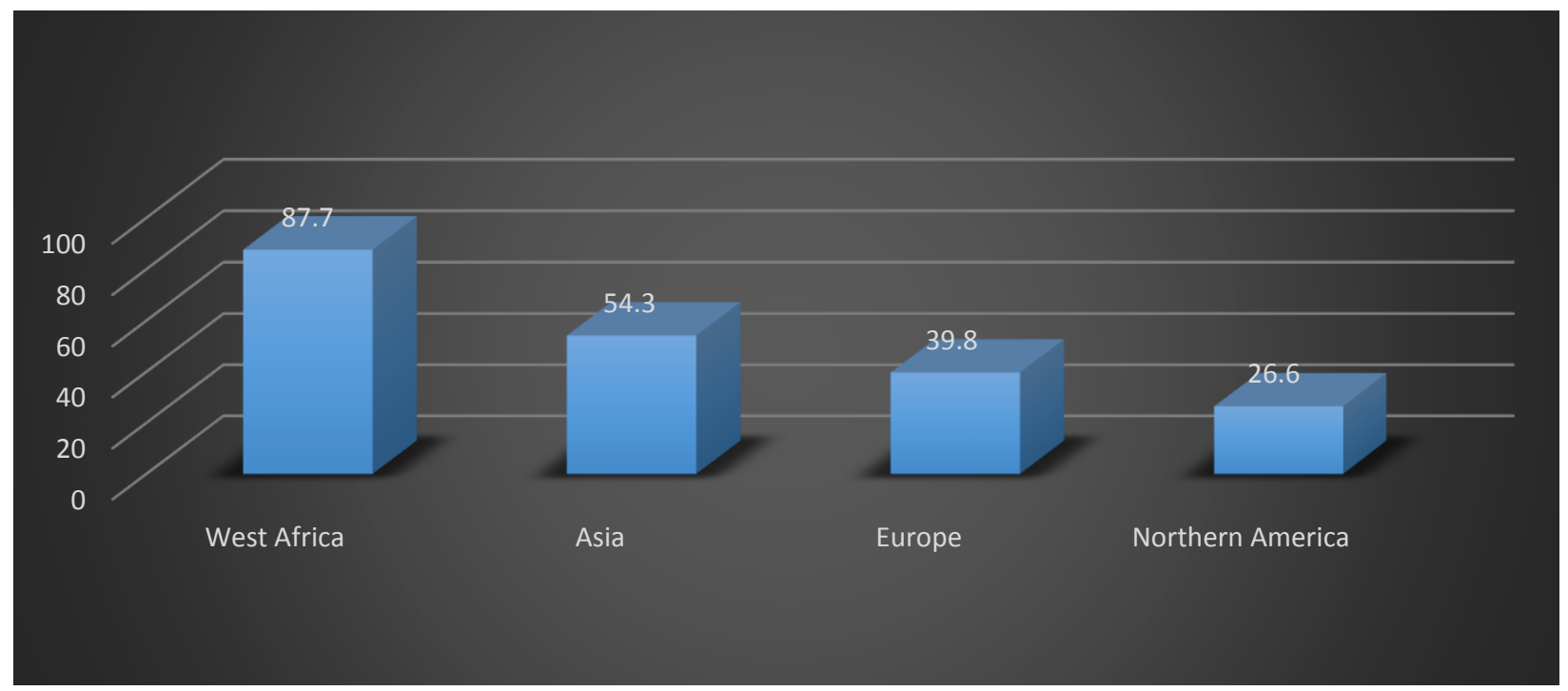

Figure 3. Global frequency of $\boldsymbol{H}$. pylori disease is higher in underdeveloped countries i.e. 87.7\% in West Africa, 54.3\% in Asia, and lower rate in developed countries i.e. 39.8\% in Europe and $26.6 \%$ in Northern America [34]

Cardia Gastric Cancer

$(260,000$ estimated cases)
Non-cardia Gastric Cancer

(691,000 estimated cases)

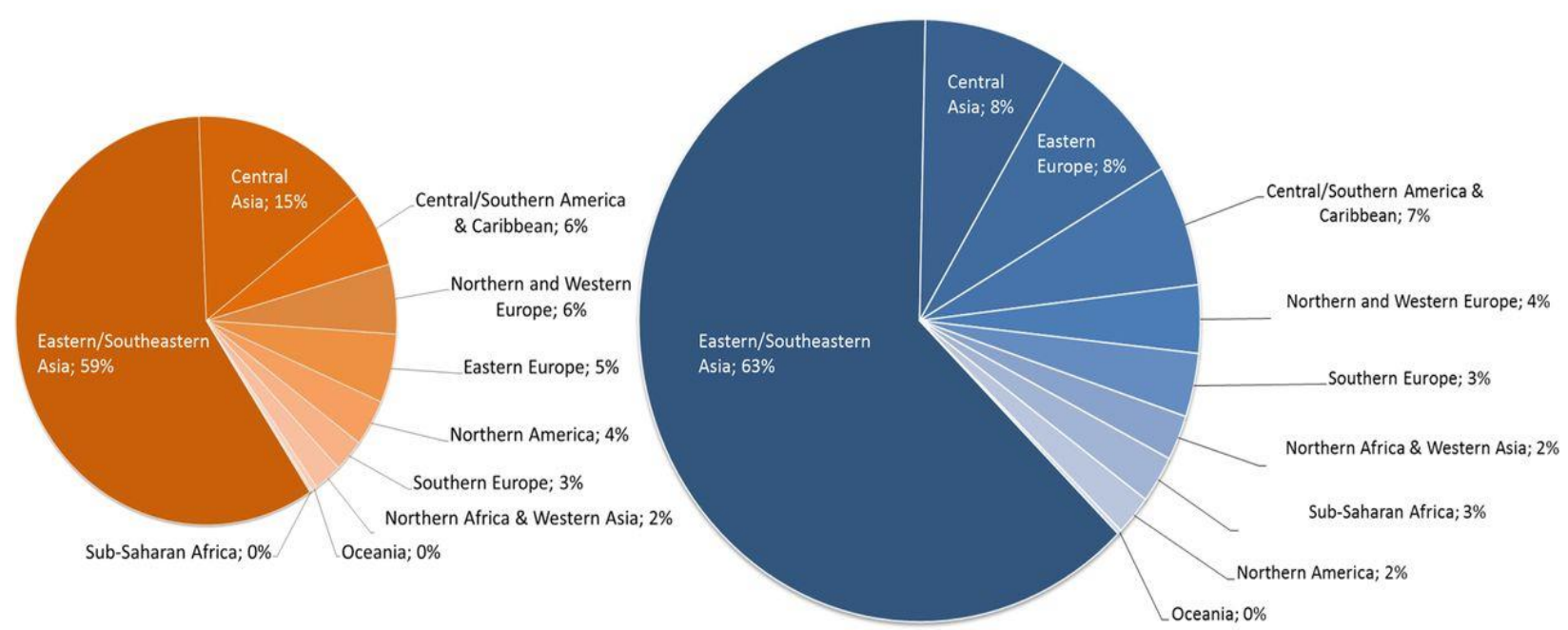

Figure 4. Globally there are 260,000 cases of CGC and 691000 cases of NCGC but the rate of both cancer is highest in Southeastern/ Eastern Asia [35]

Diseases may or may not be linked with $H$. pylori infection

H. pylori infection linked with Stomach Cancer

Gastric cancer and stomach cancer was thought to be a single term. Currently, researchers have divided these cancer into two main classes: the gastric cardia cancer, which is the tumor of the uppermost edge in stomach, where the esophagus is located and the other type of cancer is non-cardia gastric cancer which is the tumor of overall all area of stomach [10].

The association $H$. pylori with these two classes of cancer is different. Patients of noncardia gastric cancer are more prone to be 
affected by $H$. pylori infection as compared to the chances of gastric cardia cancer which may even decreasing. There are some $H$. pylori strains that have a needle-like attachment and these attachment inject a toxin in stomach lining. The $H$. pylori toxin is produced by a gene termed as cytotoxicassociated gene A or CagA in the connections where the protected stomach lining cells are present [36].

This toxin CagA changes the structure of stomach lining cells and permits bacterium to attach with the stomach cells more effortlessly with strong bond of attachment. Long-term contact of CagA causes chronic inflammation in stomach. However, strain of $H$. pylori which transmit cagA is categorized as CagA-positive.

Many epidemiologic reports proof that strain of $H$. pylori which contain CagA-positive gene may have the power to cause high rate non-cardia gastric cancer in people while the ratio of $H$. pylori CagA-positive gene reduced gastric cardia cancer risk. For instance, multiple studies around the world revealed that patient infected with $H$. pylori CagA-positive strain has the ability to double the risk of non-cardia gastric cancer. In contrast, in patient infected with $H$. pylori
CagA-negative strain has no effect on noncardia gastric cancer [37].

\section{$H$. pylori infection and diabetes mellitus}

One of the leading cause of Diabetes mellitus is dyspepsia (upper abdominal pain, bloating, nausea and burping).Beside Diabetes mellitus, dyspepsia is also deep rooted disease which is caused by $H$. pylori. The occurrence risk of $H$. pylori infection in diabetes mellitus is high [15].

The $H$. pylori mode of action becomes more active in the diabetic person when there is high concentration of glucose in blood. The patients which diabetes type 2 are more prone to $H$. pylori disease as shown in figure 5 . Hyperglycemia prompt the infection rate of $H$. pylori or in some cases $H$. pylori may get reactivated automatically and produce the symptoms of dyspepsia in diabetes [38].

New study suggested that the presences of $H$. pylori is associated with raised up level of the glycosylated hemoglobin or HbA1c. Glycosylated hemoglobin measures the amount of blood sugar (glucose) attached to hemoglobin. The association relationship was stronger in obese persons which have high Body Mass Index (BMI). The outcomes suggested that the bacterium plays a role in developing of diabetes mellitus in adults [39].

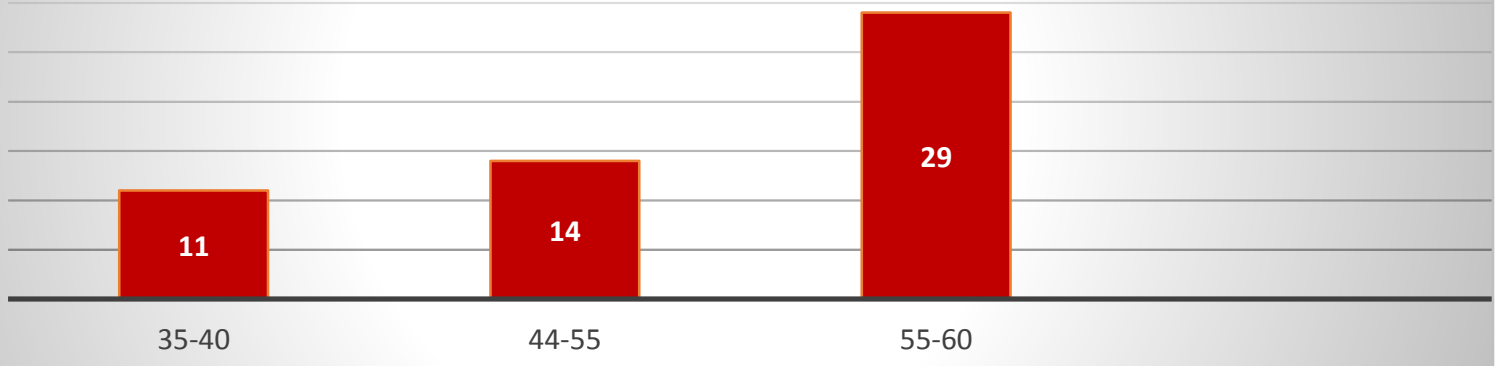

Figure 5. High $H$. pylori prevalence in type 2 diabetes mellitus patients and the rate of $H$. pylori disease that is high in age group of 50-60 and lowest in the age group of 35-40 [15]. 


\section{H. pylori relation with gastroesophageal reflux disease}

The Gastroesophageal reflux disease (GERD) are also identified as acid reflux. In GERD, there is a leakage of stomach acid and that stomach acid drives through to the esophagus and causes severe problems. The symptoms of GERD include heartburning, nausea and chest pain. The relation of $H$. pylori and GERD is inversely related to each other [40].

Epidemiologic evidence shows that people with $H$. pylori infection particularly those with CagA-positive strain are less likely to have a risk of GERD. The ratio of $H$. pylori transmission is lower in Australia, North America and Western Europe whereas GERD ratio is higher over there $[18,19,20]$. In contrast, the rate of pylori infection is higher in Europe, Africa, India, China and South America while in GERD the rate is low [21-24].

\section{Diagnosis of $\boldsymbol{H}$. pylori}

Presences of $H$. pylori in the body can be determine by certain tests and techniques which are blood test, breath test, Endoscopy and stool test.

\section{Blood test}

In blood test, blood samples are analyzed which may verify the presence of active or the previous infection of $H$. pylori infection in the body. Nonetheless, stool test and breath test are best at detecting the $H$. pylori infections.

\section{Urea breath test}

During the breath test, a pudding or liquid pill is given to patient that contains urea. The urea breaks down into radioactive carbon. The breakdown of pill in the stomach releases carbon which further comes out from the mouth. The positive test shows the high concentration of carbon dioxide $\left(\mathrm{CO}_{2}\right)$ in the breath that means $H$. pylori infection is present.

\section{Stool test}

Stool test is recently developed for detecting $H$. pylori infection. The H. pylori bacterium is diagnosed from the stool sample. In stool test, the antigen of $H$. pylori present in the stool is examined. The positive result shows that $H$. pylori is infecting the stomach.

\section{Endoscopy}

For accurate detection of $H$. pylori infection an endoscopy is performed. In endoscopy, a flexible viewing tube is inserted that moves through the mouth to end of esophagus into duodenum and stomach. During endoscopy, in biopsies a small tissue sections is removed from the lining of stomach. The biopsy sample is placed on a special slide covering urea. Change in color consequences that the urea is smashed by $H$. pylori in the biopsy, which results that there is an infection of $H$. pylori in the stomach [9].

\section{Treatment of $\boldsymbol{H}$. pylori}

The chronic infection of $H$. pylori declines the natural defense lining of the stomach and results to acid formation by ulcerating action. H. pylori treatment can be taken from both routes natural and conventional.

\section{Conventional treatment}

For the last two decades, triple therapy mechanism was used to eradicate $\mathrm{H}$. pylori infection. In triple therapy, medications for neutralizing stomach acidity and decrease the secretion of stomach acid were used such medicines contains proton pump inhibitors (PPIs), clarithromycin, ranitidine bismuth citrate and amoxicillin. Due to high antibiotic resistance the efficiency rate of triple therapy decreased to $70 \%$ [41]. In recent years, plenty of studies suggested that eradication of $H$. pylori through second line therapies is still possible. The second line therapies include two methods i.e. sequential therapy and quadruple therapy [42]. In sequential therapy similar antibiotic such as PPI, amoxicillin and clarithromycin which were used in standard triple therapy. But the combination of the medicine has been changed i.e. firstly 
amoxicillin is given instead of PPI because it disturbs the cell wall of bacteria [43]. In quadruple therapy, PPI, amoxicillin and clarithromycin is given but without bismuth for ten days. This therapy is effective for those countries in which there is high resistances of $H$. pylori against clarithromycin [44].

\section{Natural treatment}

Eradication of $H$. pylori is challenging because the clever bacterium is proficient to develop resistance to a common antibiotics. Along with the medication, $H$. pylori natural treatment can help to destroy infection and also reduces inflammation of the stomach lining as shown in figure 6. Some study suggested that bifid bacteria which are probiotics living microorganisms often have health benefits in treating gastrointestinal infection. A study on mice shows that green tea decreased both inflammation of $H$. pylori in mice as well as number of bacteria. According to an experiment based study, the gel inside the leaves of an aloe Vera plant has effective results on inhibiting growth and killing $H$. pylori strains. One other study demonstrates that honey has anti H. pylori property [29]. Recent study of fungal properties demonstrates that Antrodia camphorata a mushroom in China displays anti-inflammatory activity against $H$. pylori in human gastric mucosa [45].

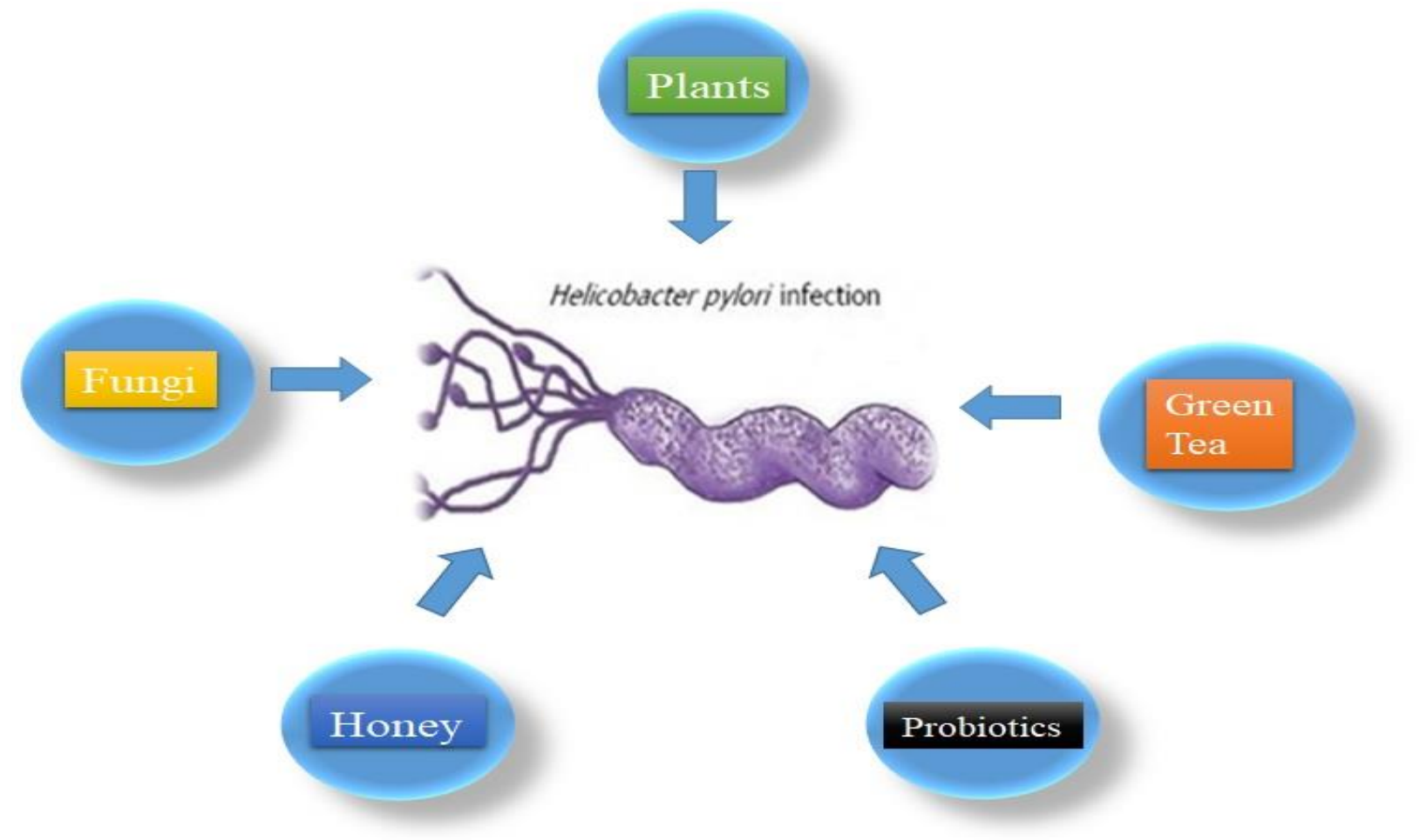

Figure 6. Eradication of Helicobacter pylori infection through natural treatment. Using aloe Vera, green tea, honey and probiotics along with the antibiotics has effective results on inhibiting and killing $H$. pylori strains [45].

\section{Prevention of $\boldsymbol{H}$.pylori}

Approximately over three billion (50\%) of the total inhabitants are identified to be infected $H$. pylori and likely no vaccine available that's why it is difficult for people to stay safe from bacterium. Currently, effective recommendations to prevent infections are to wash hands frequently, 
Drink clean water, Eat properly cooked food , Stop smoking and reduce intake of alcohol [29].

\section{Conclusion}

Good nutrition plays a significant role in good mental and physical health. Extensive studies shows that there is a link between microbes and human health. There are trillion of microorganism, not all of them harm human but those who do can effect human as well as the food they intake. H. pylori possess gram-negative helical morphology that is found in stomach, cause chronic gastritis with long lasting stomach inflammation. The transmission of bacterial infection is through saliva, fecal material, vomiting and by contaminated food and water. Infectious complications of $H$. pylori are stomach ulcers, inflammation in stomach linings and cancer of stomach. $H$. pylori bacterium is commonly present in approximately half of the total human population. The frequency of H. pylori infection varies from high in underdeveloped countries to low in developed countries. H. pylori transmission is not a hereditary disease. About 70\% children in underdeveloped countries may suffer from $H$. pylori infection. The infection in children may be due to not eating cleaned and properly cooked food, by drinking contaminated water and by not washing hands properly. $H$. pylori bacterium secretes urease enzyme which helps them to survive in the harsh nature of gut. The world's second most fatal cancer is gastric cancer that is more common in South America and Asia than the western countries and United State. Some stains of $H$. pylori bacterium have a needlelike attachment through which inject a toxin which is produced by a gene cagA. The cagA cause long lasting attachment to stomach lining which results in chronic inflammation. The patients with diabetes type 2 are more prone to $H$. pylori infection. Hyperglycemia condition can induces the infection rate of $H$. pylori producing the symptoms of dyspepsia in diabetes. Recently some study demonstrated that the presence of $H$. pylori bacteria is linked with increased level of the glycosylated hemoglobin or HbA1c. The prevalence of $H$. pylori is inversely related to gastroesophageal reflux disease. Epidemiologic evidence shows that people with $H$. pylori infection especially those with cagA-positive strains are less likely to have GERD. The link between NAFLD and $H$. pylori infection is controversial but recent study suggested that there is an association between NAFLD and the H. pylori cagAnegative strain. $H$. pylori disease can be diagnosed by upper endoscopy or EGD, breath test and stool culture. Second line therapies such as sequential therapy and quadruple therapy are used for treating $H$. pylori infection. Some natural substances are also used with antibiotic to increase its efficiency treatment of $H$. pylori which are probiotic, drinking green tea, using honey, olive oil, broccoli and licorice root in diet have some antibacterial properties against $H$. pylori. The rate of $H$. pylori attack can be decreased by improving household hygienic and sanitary infrastructure.

\section{Authors' contributions}

Conceived and designed the experiments: $\mathrm{M}$ S Shahzad \& M Hassan, Performed the experiments: M Hassan \& HA Rahman, Analyzed the data: M Ibrahim \& MA Razaq, Contributed reagents/ materials/ analysis tools: R Ahmed \& A Arif, Wrote the paper: M Hassan.

\section{Reference}

1. Abbas M, Sharif FA, Osman SM, Osman AM, El Sanousi SM, Magzoub M \& Ibrahim ME (2018). Prevalence and Associated Symptoms of Helicobacter pylori Infection among Schoolchildren in Kassala State, East of Sudan. Interdiscip Perspect Infect Dis.

2. National Academies of Sciences, Engineering, and Medicine 
(2017). Microbiomes of the built environment: a research agenda for indoor microbiology, human health, and buildings. National Academies Press.

3. Hua JS, Zheng PY \& Ho B (1999). Species differentiation and identification in the genus of Helicobacter. World J Gastroenterol 5(1): 7.

4. Cover TL \& Blaser MJ (2009). Helicobacter pylori in health and disease. Gastroenterol 136(6): 1863 1873.

5. Contreras $\mathrm{M}$, Fernández-Delgado $\mathrm{M}$, Reyes N, García-Amado MA, Rojas H \& Michelangeli F (2015). Helicobacter pylori Infection in rural and urban dyspeptic patients from Venezuela. Am J Trop Med Hyg 93(4): 730-732.

6. Brown LM (2000). Helicobacter pylori: epidemiology and routes of transmission. Epidemiol Rev 22(2): 283297.

7. Fuccio L, Eusebi LH \& Bazzoli F (2010). Gastric cancer, Helicobacter pylori infection and other risk factors. World $J$ of Gastrointes Oncol 2(9): 342.

8. Sonnenberg A (2013). Historic changes of Helicobacter pylori-associated diseases. Aliment. Pharmacol. Ther 38(4): 329-42.

9. Abadi ATB (2018). Diagnosis of Helicobacter pylori using invasive and noninvasive approaches. Hindawi $J$ of Pathogens, pp 1-13.

10. Ferlay J, Shin HR, Bray F, Forman D, Mathers C, Parkin DM \& International Agency for Research on Cancer. GLOBOCAN (2008) ver. 2.0. Cancer incidence and mortality worldwide:
IARC Cancer Base No. 10 [Internet]. Lyon: IARC; c2010.[cited 2012 Jul 12].

11. Kusters JG, van Vliet AH \& Kuipers EJ (2006). Pathogenesis of Helicobacter pylori infection. Clin. Microbiol. Rev 19(3): 449-490.

12. Lagergren $\mathrm{F}$, Xie $\mathrm{SH}$, Mattsson $\mathrm{F} \&$ Lagergren J (2018). Updated incidence trends in cardia and non-cardia gastric adenocarcinoma in Sweden. Acta Oncol 57(9): 1173-1178.

13. Chen YY, Fang WH, Wang CC, Kao TW, Chang YW, Wu CJ, Zhou YC, Sun YS \& Chen WL (2019). Helicobacter pylori infection increases risk of incident metabolic syndrome and diabetes: A cohort study. PloS One 14(2): e0208913.

14. Ayar Y, Pamukçu Ö, Eroğlu H, Kalkan Erol K, Ilhan A \& Kocaman O (2015). Relationship between Helicobacter pylori infections in diabetic patients and inflammations, metabolic syndrome, and complications. J Chronic Dis.

15. Devrajani BR, Shah SZ, Soomro AA \& Devrajani T (2010). Type 2 diabetes mellitus: A risk factor for Helicobacter pylori infection: A hospital based casecontrol study. Int $J$ Diabetes Dev C 30(1): 22.

16. Serena $\mathrm{S}$, Michele $\mathrm{R}$, Chiara $\mathrm{M}$, Gioacchino L, Lorella F, Tiziana M \& Francesco DM (2018). Relationship between Helicobacter pylori infection and GERD. Acta Biomed 89 (Suppl 8), 40.

17. Zullo A, Hassan C, Repici A, Bruzzese V (2013). Helicobacter pylori eradication and reflux disease onset: Did gastric acid get" crazy" WJG 19(6): 786. 
18. Talley N, Boyce P \& Jones M (1998). Identification of distinct upper and lower gastrointestinal symptom groupings in an urban population. Gut 42(5): 690695.

19. Hoang TT, Bengtsson C, Phung DC, Sörberg M \& Granström M (2005). Seroprevalence of Helicobacter pylori infection in urban and rural Vietnam. Clin Diagn Lab Immunol 12(1): 81-85

20. Nwokediuko S (2009). Gastroesophageal reflux disease: a population based study. Gastroent Res Pract 2(3): 152.

21. Sitaraman R (2015). Allergies, Helicobacter pylori and the continental enigmas. Front Microbiol 6: 578.

22. Reshetnikov OV, Häivä VM, Granberg C, Kurilovich SA \& Babin VP (2001). Seroprevalence of Helicobacter pylori infection in Siberia. Helicobacter 6(4): 331-336.

23. Wong WM, Lai KC, Lam KF, Hui WM, Hu WH, Lam CL, Xia HH, Huang JQ, Chan CK, Lam SK \& Wong BC (2003). Prevalence, clinical spectrum and health care utilization of gastro-oesophageal reflux disease in a Chinese population: a population-based study. Aliment Pharmacol Ther 18(6), 595-604.

24. Shah SS, Bhatia SJ \& Mistry FP (2001). Epidemiology of dyspepsia in the general population in Mumbai. Indian $J$ Gastroenterol 20(3), 103-106.

25. Chen CX, Mao YS, Foster P, Zhu ZW, Du J \& Guo CY (2016). Possible association between Helicobacter pylori infection and nonalcoholic fatty liver disease. Appl Physiol Nutr Me 42(3): 295-301.

26. Mantovani A (2017). Nonalcoholic fatty liver disease (NAFLD) and risk of cardiac arrhythmias: a new aspect of the liver-heart axis. J Clin Transl Hepatol 5(2): 134.

27. Tang DM \& Kumar S (2017). The association between Helicobacter pylori infection and nonalcoholic fatty liver disease. Curr Gastroenterol Rep 19(2): 5.

28. Diaconu S, Predescu A, Moldoveanu A, Pop CS \& Fierbințeanu-Braticevici C (2017). Helicobacter pylori infection: old and new. J Med Life 10(2): 112.

29. Yucel O (2014). Prevention of Helicobacter pylori infection in childhood. WJG 20(30): 10348.

30. Karlık B, Avcı A \& Yabanıgül A (2009). Classification of helicobacter pylori according to national strains using bayesian learning. Math comput Appl 14(3): 241-251.

31. Mobley HL, Mendz GL \& Hazell SL (2001). Restriction and Modification Systems Helicobacter pylori. Physiol Genomics ASM press.

32. Reshetnyak VI \& Reshetnyak TM (2017). Significance of dormant forms of Helicobacter pylori in ulcerogenesis. World J Gastroenterol 23(27): 4867.

33. Abbas M, Sharif FA, Osman SM, Osman AM, El Sanousi SM \& Magzoub M (2018). Prevalence and Associated Symptoms of Helicobacter pylori Infection among Schoolchildren in Kassala State, East of Sudan. Interdiscip Perspect Infect Dis. 
34. Hooi JK, Lai WY, Ng WK, Suen MM, Underwood FE, Tanyingoh D, Malfertheiner P, Graham DY, Wong VW, Wu JC \& Chan FK (2017). Global prevalence of Helicobacter pylori infection: systematic review and meta analysis. Gastroenterol 153(2): 420-429.

35. Colquhoun A, Arnold M, Ferlay J, Goodman KJ, Forman D \& Soerjomataram I (2015). Global patterns of cardia and non-cardia gastric cancer incidence in 2012. Gut 64(12): 18811888.

36. Bagnoli F, Buti L, Tompkins L, Covacci A \& Amieva MR (2005). Helicobacter pylori CagA induces a transition from polarized to invasive phenotypes in MDCK cells. Proc Natl Acad Sci USA 102(45): 16339-16344.

37. Huang JQ, Zheng GF, Sumanac K, Irvine EJ \& Hunt RH (2003). Metaanalysis of the relationship between cagA seropositivity and gastric cancer. Gastroenterol 125(6): 1636-1644.

38. Shera AS, Jawad F \& Maqsood A (2007). Prevalence of diabetes in Pakistan. Diabetes Res Clin Pract 76(2): 219-222.

39. Jeon CY, Haan MN, Cheng C, Clayton ER, Mayeda ER, Miller JW \& Aiello AE (2012). Helicobacter pylori infection is associated with an increased rate of diabetes. Diabetes Care 35(3): 520-525.

40. Peek RM (2004). Helicobacter pylori and gastroesophageal reflux disease. Curr Treat Opti in Gastroenterol 7(1): 59-70.

41. De Francesco V, Zullo A, Ierardi E \& Vaira D (2009). Minimal inhibitory concentration (MIC) values and different point mutations in the $23 \mathrm{~S}$ rRNA gene for clarithromycin resistance in Helicobacter pylori.Dig Liver Dis Title 41(8): 610-611.

42. Lu C, Sang J, He H, Wan X, Lin Y, Li L \& $\quad \mathrm{Yu} \quad \mathrm{C}(2016) . \quad$ Probiotic supplementation does not improve eradication rate of Helicobacter pylori infection compared to placebo based on standard therapy: a meta-analysis. $S c i$ Rep 6: 23522.

43. Webber MA, Piddock LJ (2003). The importance of efflux pumps in bacterial antibiotic resistance. $J$ Antimicrob Chemother 51(1): 9-11.

44. Goderska K, Pena SA \& Alarcon T (2018). Helicobacter pylori treatment: antibiotics or probiotics. Appl Microbiol Biotechno 102(1): 1-7.

45. Chen YH, Tsai WH, Wu HY, Chen CY, Yeh WL, Chen YH \& Lin TL (2019). Probiotic Lactobacillus spp. Act against Helicobacter pylori induced Inflammation. J Clin Med 8(1): 90. 